\title{
Assessment of Respiratory Muscle Weakness in Subjects With Neuromuscular Disease
}

\author{
Maria João P Oliveira MD, Fernanda Rodrigues MD, João Firmino-Machado MD, \\ Inês T Ladeira MD, Ricardo Lima MD, Sara D Conde MD, and Miguel Guimarães MD
}

\begin{abstract}
INTRODUCTION: Neuromuscular diseases (NMD) are a group of rare heterogeneous disorders that may be accompanied by respiratory muscle weakness. The simplest measurements of respiratory muscle strength are maximum inspiratory pressure $\left(\mathbf{P}_{\text {Imax }}\right)$ and maximum expiratory pressure $\left(\mathbf{P}_{\text {Emax }}\right)$ of the mouth. Inspiratory muscle weakness can also be evaluated by the sniff test (sniff nasal inspiratory pressure method). This study tested the agreements in $\mathbf{P}_{\mathbf{I m a x}}$ and $\mathbf{P}_{\text {Emax }}$ (measured by using a plethysmograph and portable equipment) as well as the correlations of $\mathbf{P}_{I \max }$ and $\mathbf{P}_{\text {Emax }}$ by using the sniff nasal inspiratory pressure method, lung function, and arterial blood gas parameters in subjects with NMD. METHODS: This prospective, noninterventional study measured respiratory parameters in all the subjects with NMD who underwent measurement of maximum respiratory pressures. RESULTS: A total of 55 subjects with NMD were included. There were no statistically significant differences in $\mathbf{P}_{\text {Imax }}$ and $\mathbf{P}_{\text {Emax }}$ measured by using a plethysmograph and portable equipment. Moreover, $P_{\text {Imax }}$ showed a good correlation with the sniff nasal inspiratory pressure method. CONCLUSIONS: Measurements of $\mathbf{P}_{\text {Imax }}$ and $\mathbf{P}_{\text {Emax }}$ by using portable equipment were equivalent to those performed by using the accepted standard, plethysmography, in the subjects with NMD. Noninvasive evaluation of the sniff test with the portable equipment correlates with $\mathbf{P}_{\text {Imax }}$, which makes this approach a good method for measuring the maximum strength of inspiratory muscles in patients with NMD. Key words: neuromuscular diseases; maximum inspiratory pressure; maximum expiratory pressure; sniff; sniff nasal inspiratory pressure; respiratory muscle weakness. [Respir Care 2018;63(10):1223-1230. (C) 2018 Daedalus Enterprises]
\end{abstract}

\section{Introduction}

Neuromuscular diseases (NMD) are a group of rare heterogeneous disorders that affect the function of peripheral nervous system components ${ }^{1}$ and may be accompanied by respiratory muscle weakness. ${ }^{2-4}$ Some NMDs respond to specific therapies, whereas others are incompletely treated. ${ }^{3}$ Early detection of respiratory muscle weakness is essential because it may serve as an indication for diagnosis and

Drs Oliveira, Rodrigues, Ladeira, Lima, Conde, and Guimarães are affiliated with the Department of Pulmonology, Centro Hospitalar de Vila Nova de Gaia e Espinho, Entidade Pública Empresarial (EPE), Vila Nova de Gaia, Portugal. Dr Firmino-Machado is affiliated with the Public Health Unit, Agrupamento de Centros de Saúde (ACeS) Porto Ocidental, Porto, Portugal.

Dr Oliveira presented research data at the European Respiratory Congress 2016, held 3-7 September 2016, in London, United Kingdom. prognosis, and for the implementation of therapeutic strategies. ${ }^{3,5-7}$ Respiratory muscle weakness, defined as the persistent incapacity of respiratory muscles to perform their mechanical functions or to generate sufficient pressure, is a potentially life-threatening condition. ${ }^{8}$ Unlike fatigue, however, muscle weakness is not reversible with rest. ${ }^{9}$

The simplest scientific measurements of respiratory muscle strength are the maximum inspiratory pressure $\left(\mathrm{P}_{\text {Imax }}\right)$ and the maximum expiratory pressure $\left(\mathrm{P}_{\text {Emax }}\right)$ of the mouth. ${ }^{10}$ In standard clinical practice, inspiratory muscle

\footnotetext{
The authors have disclosed no conflicts of interest.

Correspondence: Maria João Oliveira MD, Serviço de Pneumologia, Centro Hospitalar de Vila Nova de Gaia e Espinho (CHVNG/E), Rua Conceição Fernandes, 4434-502 Vila Nova de Gaia, Portugal. E-mail: 6oliveiramariajoao@gmail.com.
}

DOI: $10.4187 /$ respcare. 06136 
weakness is evaluated by measuring $\mathrm{P}_{\text {Imax }},{ }^{9}$ the classic volitional test of inspiratory muscle strength, ${ }^{4,8,11-13}$ for which there are reference values. ${ }^{14-17} \mathrm{P}_{\text {Imax }}$ is defined as the highest mouth pressure sustained for $1 \mathrm{~s}$ during a maximum inspiratory effort against a quasi-occlusive barrier. ${ }^{4,13,16,17}$ Although $\mathrm{P}_{\text {Imax }}$ is simple to measure, the maneuver is difficult for many patients to perform and requires a hermetic seal around the mouthpiece. ${ }^{8}$ Thus, $\mathrm{P}_{\text {Imax }}$ may be underestimated in patients with problems in the upper airways $^{9}$ and those with true muscle weakness ${ }^{8}$ because the maneuver may not be truly maximal ${ }^{2,4,9,12,17-19}$ or facial muscle weakness may introduce air leaks. ${ }^{8}$

Moreover, technical factors, most notably the type of mouthpiece and the time allowed for learning the maneuver, may differ among laboratories and result in differences in measured $\mathrm{P}_{\text {Imax }} \cdot{ }^{19}$ One alternative is the sniff test, which is more natural for most patients and easier to perform. ${ }^{8,11-14,18,19}$ The sniff test has been shown to assess diaphragm strength by measuring transdiaphragmatic pressure and to assess global inspiratory muscle strength by measuring esophageal pressure. ${ }^{8}$ More recently, the sniff nasal inspiratory pressure method was proposed as a noninvasive test of inspiratory muscle strength. ${ }^{20}$ This very simple procedure consists of a short, sharp, voluntary inspiratory maneuver through one or both unoccluded nostrils. ${ }^{9,17}$ Multiple tests of respiratory muscle function increase the diagnostic precision of respiratory muscle weakness. ${ }^{21}$ In addition to assessing respiratory muscle weakness in patients with NMD, the lung function and arterial blood gas of such patients should be evaluated because the results of these tests may provide important information on disease stratification and treatment.

Maximum respiratory pressures can be evaluated by using several types of equipment. Our laboratory standard for measuring maximum respiratory pressures is the plethysmograph, although portable equipment has also shown accuracy and reproducibility. ${ }^{10,22}$ To our knowledge, no study has evaluated the agreement between $\mathrm{P}_{\text {Imax }}$ and $\mathrm{P}_{\text {Emax }}$ measured with a plethysmograph and portable equipment, particularly in subjects with NMD and different diagnoses. This study, therefore, compared $\mathrm{P}_{\text {Imax }}$ and $\mathrm{P}_{\text {Emax }}$ measured with a plethysmograph and portable equipment. In addition, the correlations of these parameters with the sniff nasal inspiratory pressure method, $\mathrm{FVC}, \mathrm{FEV}_{1}$, total lung capacity (TLC), $\mathrm{P}_{\mathrm{aO}}$, and $\mathrm{P}_{\mathrm{aCO}}$ were evaluated in subjects with NMD.

\section{Methods}

\section{Design and Population}

This prospective, noninterventional study included all the subjects diagnosed with NMD by a neurologist who

\section{QUICK LOOK}

\section{Current knowledge}

Neuromuscular diseases are a rare heterogeneous group of disorders in which respiratory muscle weakness, a life-threatening condition, can be present. In standard clinical practice, inspiratory muscle weakness is evaluated by assessing maximum inspiratory pressure, the sniff nasal inspiratory pressure method is an alternative maneuver to maximum inspiratory pressure. There are several types of equipment to evaluate maximum respiratory pressures.

\section{What this paper contributes to our knowledge}

The maximum inspiratory pressure and maximum expiratory pressure assessment in a plethysmograph and with portable equipment were equivalent. The sniff nasal inspiratory pressure maneuver obtained, in a noninvasive manner, was a very good measurement of the maximum strength of the inspiratory muscles and correlated with the maximum inspiratory pressure measurement.

underwent measurement of maximum respiratory pressures $\left(\mathrm{P}_{\text {Imax }}, \mathrm{P}_{\text {Emax }}\right.$, and sniff nasal inspiratory pressure method) in the pulmonary function testing laboratory of our institution. Patients with nasal anatomic abnormalities or excessive daytime sleepiness, or who were uncooperative in performing the maneuvers or who could not enter the plethysmograph were excluded. Obstructive sleep apnea, which frequently accompanies NMDs, was screened for by using the Epworth Sleepiness Scale, ${ }^{23}$ with scores $>10$ considered excessive daytime sleepiness. ${ }^{23}$ All the study subjects underwent plethysmography and maximum respiratory pressure measurements while in the sitting position, within a single testing session between $9 \mathrm{Am}$ and noon. All the subjects provided written informed consent, and the study protocol was approved by the institutional ethics committee of our institution. The study was performed in the Pulmonology Department, Centro Hospitalar de Vila Nova de Gaia e Espinho, Entidade Pública Empresarial, Vila Nova de Gaia, Portugal.

\section{Variables Analyzed}

Anthropometric parameters included measurements of body weight and height of each individual on a seca model 764 anthropometric mechanical scale with a stadiometer (seca, Birmingham, United Kingdom). $\mathrm{P}_{\text {Imax }}$ and $\mathrm{P}_{\text {Emax }}$ were each measured on both a plethysmograph (Jaeger Master Lab, Würzburg, Germany) and portable equipment 
(MicroRPM, Smart Medical, Gloucestershire, United Kingdom)), with maneuvers performed by using rigid tubular mouthpieces. The $\mathrm{P}_{\text {Imax }}$ maneuver was performed with the cheeks supported by both hands, followed by measurement of residual volume, whereas $\mathrm{P}_{\mathrm{Emax}}$ was determined from TLC. The maximum values measured by following 3 valid and reproducible maneuvers of peak pressures (difference of $<5 \%$ ) were included in the analysis and compared with reference values for a Mediterranean population. ${ }^{1}$ Each subject performed a maximum of 10 maneuvers; if none of the maneuvers were valid, then $\mathrm{P}_{\text {Imax }}$ or $\mathrm{P}_{\mathrm{Emax}}$ was considered unevaluable. The order of testing on the plethysmograph and the portable device was randomly determined.

The sniff nasal inspiratory pressure was measured on the same portable device by using disposable nasal probes and after measuring $\mathrm{P}_{\text {Imax }}$ and $\mathrm{P}_{\text {Emax }}$ on this device. An appropriately sized nasal probe, as verified by ensuring the absence of air leaks during sniffs was inserted into the nostril that seemed most clinically patent. Without previous training, the subject was asked to perform short, sharp sniffs of maximum intensity from functional residual capacity with the mouth closed. Normal breathing was allowed between trials, with at least 10 trials performed. The highest value for each sniff nasal inspiratory pressure measurement was recorded and compared with reference values. ${ }^{18}$

Pulmonary function test variables were determined by forced spirometry in accordance with American Thoracic Society/European Respiratory Society guidelines, ${ }^{24}$ by using Global Lung Function Initiative 2012 reference values, ${ }^{25}$ followed by measurements of static lung volumes and airway resistance by using body plethysmography (Jaeger). The pulmonary function test variables analyzed were FEV $1, F V C$, and TLC. Arterial blood gases $\left(\mathrm{P}_{\mathrm{aO}_{2}}\right.$ and $\left.\mathrm{P}_{\mathrm{aCO}}\right)$ were measured by using an ABL90 FLEX blood gas analyzer (Radiometer America, Brea, California). All examinations were performed by technicians in our laboratory, all of whom had previous training.

\section{Statistical Analysis}

Quantitative variables were reported as mean \pm SD. Normality was assessed by using skewness and kurtosis measures. $\mathrm{P}_{\text {Imax }}$ and $\mathrm{P}_{\text {Emax }}$ measured with the plethysmograph and the portable device were compared by using paired samples Student $t$ tests, with differences between the 2 measurement methods reported as the mean and corresponding $95 \%$ CIs. The levels of agreement of $\mathrm{P}_{\text {Imax }}$ and $\mathrm{P}_{\mathrm{Emax}}$ measured with the plethysmograph and the portable device were assessed by Bland-Altman plots, ${ }^{26}$ which show the differences between the measurements and the average of the measurements. Agreement lines were plotted by using the formula: mean difference $\pm 1.96 \times \mathrm{SD}$ of the measured differences, which yielded 95\% CIs for the mean differences and agreement lines.

Pearson correlation (r) analysis was used to test the associations between $\mathrm{P}_{\mathrm{Imax}} / \mathrm{P}_{\mathrm{Emax}}$ and the respiratory variables sniff nasal inspiratory pressure, $\mathrm{FVC}, \mathrm{FEV}_{1}$, TLC, $\mathrm{P}_{\mathrm{aO}}$, and $\mathrm{P}_{\mathrm{aCO}_{2}}$. Correlation coefficients of $0-0.25,0.25-$ $0.50,0.50-0.75,0.75-0.90$, and $0.90-1.0$ were considered very weak, weak, moderate, strong, and very strong, respectively. ${ }^{27}$ All statistical analyses were performed by using IBM SPSS Statistics version 21 (SPSS, Chicago, Illinois) and MedCalc version 18.2.1 (MedCalc Software, Mariakerke, Belgium). All $P$ values were 2-tailed, with a $P$ value $<.05$ indicating statistical significance.

\section{Sample Size Calculation}

The sample size was calculated from previous data by using PS software (version 3.1.2, Vanderbilt University, Nashville, Tennessee). When assuming an SD of 24,9 a minimum detectable difference between the $\mathrm{P}_{\text {Imax }}$ values determined by using both types of equipment with $15 \mathrm{~cm} \mathrm{H}_{2} \mathrm{O},{ }^{4}$ a power of $90 \%$, and a type 1 error of 0.05 , a sample size of 55 subjects was regarded as sufficient.

\section{Results}

Of the 68 subjects recruited, 13 were excluded, 8 because of their inability to enter the plethysmograph, 4 because of their inability to perform the required maneuvers, and 1 because of nasal anatomic abnormalities. The general characteristics of the 55 included subjects with NMD are shown in Table 1 and their diagnoses are listed in Table 2. Most of the subjects $(60 \%)$ were men, and the mean age of all the subjects was $55 \mathrm{y}$ (range, 18-83 y). The mean \pm SD FVC was $67 \pm 25 \%$ of predicted, with 38 subjects $(69 \%)$ with an FVC of $<80 \%$ of predicted.

$\mathrm{P}_{\text {Imax }}$ values measured with the plethysmograph (43.1 $\mathrm{cm} \mathrm{H}_{2} \mathrm{O}$ ) and the portable device $\left(44.6 \mathrm{~cm} \mathrm{H}_{2} \mathrm{O}\right.$ ) did not differ significantly, with a mean difference of $1.5 \mathrm{~cm} \mathrm{H}_{2} \mathrm{O}\left(95 \% \mathrm{CI}-13.3\right.$ to $\left.16.3 \mathrm{~cm} \mathrm{H}_{2} \mathrm{O}\right)$. In addition, $\mathrm{P}_{\text {Emax }}$ values measured with the plethysmograph $\left(63.6 \mathrm{~cm} \mathrm{H}_{2} \mathrm{O}\right)$ and the portable device $\left(62.2 \mathrm{~cm} \mathrm{H}_{2} \mathrm{O}\right)$ did not differ significantly, with a mean difference of $-1.4 \mathrm{~cm} \mathrm{H}_{2} \mathrm{O}\left(95 \% \mathrm{CI}-23.3\right.$ to $\left.20.5 \mathrm{~cm} \mathrm{H}_{2} \mathrm{O}\right)$. The Bland-Altman plots for $\mathrm{P}_{\text {Imax }}$ (Fig. 1) and $\mathrm{P}_{\text {Emax }}$ (Fig. 2) showed that the mean differences between the 2 types of equipment did not differ significantly from zero. Most of the data in Fig. 1 (91\%) and Fig. 2 (96\%) fell within the lines of agreement. Of the 17 subjects with FVC $>80 \%$ of predicted, only 2 had normal $\mathrm{P}_{\text {Imax }}$ in both measurements (plethysmograph and MicroRPM); 4 had normal $\mathrm{P}_{\mathrm{Emax}}$ in both measurements (plethysmograph and MicroRPM); and 3, including the 2 with normal $P_{\text {Imax }}$, had normal sniff nasal inspiratory pressure. 
Table 1. General Characteristics of the Study Population

\begin{tabular}{|c|c|}
\hline Subjects' Characteristics & Results \\
\hline \multicolumn{2}{|l|}{ Demographic data } \\
\hline Age, mean $\pm \mathrm{SD} y$ & $55.1 \pm 17.5$ \\
\hline Men, $n(\%)$ & $33(60)$ \\
\hline Body mass index, mean $\pm \mathrm{SD} \mathrm{kg} / \mathrm{m}^{2}$ & $27.4 \pm 5.7$ \\
\hline \multicolumn{2}{|l|}{$\mathrm{PFT}$ and $\mathrm{ABG}$ data, mean $\pm \mathrm{SD}$} \\
\hline $\mathrm{FVC}, \%$ of predicted & $67.4 \pm 24.9$ \\
\hline FVC, L & $2.3 \pm 0.9$ \\
\hline $\mathrm{FEV}_{1}, \%$ of predicted & $72.3 \pm 25.1$ \\
\hline $\mathrm{FEV}_{1}, \mathrm{~L}$ & $1.9 \pm 0.7$ \\
\hline TLC, $\%$ of predicted & $86.4 \pm 18.7$ \\
\hline TLC, L & $4.6 \pm 1.2$ \\
\hline $\mathrm{P}_{\mathrm{aCO}}, \mathrm{mm} \mathrm{Hg}$ & $42.9 \pm 5.4$ \\
\hline $\mathrm{P}_{\mathrm{aO}_{2}}, \mathrm{~mm} \mathrm{Hg}$ & $75.8 \pm 11.3$ \\
\hline \multicolumn{2}{|l|}{ Muscle strength testing data, mean $\pm \mathrm{SD} \mathrm{cm} \mathrm{H}_{2} \mathrm{O}$} \\
\hline $\mathrm{P}_{\text {Imax } 1}$ & $43.1 \pm 22.7$ \\
\hline $\mathrm{P}_{\text {Imax } 2}$ & $44.6 \pm 27.1$ \\
\hline $\mathrm{P}_{\text {Emax } 1}$ & $63.6 \pm 30.8$ \\
\hline $\mathrm{P}_{\mathrm{Emax} 2}$ & $62.2 \pm 31.6$ \\
\hline SNIP test & $56.3 \pm 29.2$ \\
\hline \multicolumn{2}{|l|}{$N=55$} \\
\hline \multicolumn{2}{|l|}{$\mathrm{PFT}=$ pulmonary function test } \\
\hline \multirow{2}{*}{\multicolumn{2}{|c|}{$\begin{array}{l}\mathrm{ABG}=\text { arterial blood gas } \\
\mathrm{TLC}=\text { total lung capacity }\end{array}$}} \\
\hline & \\
\hline \multicolumn{2}{|l|}{$\mathrm{P}_{\operatorname{Imax1}}=$ maximum inspiratory pressure measured with plethysmograph } \\
\hline \multicolumn{2}{|l|}{$\mathrm{P}_{\operatorname{Imax} 2}=$ maximum inspiratory pressure measured with MicroRPM } \\
\hline \multicolumn{2}{|l|}{$\mathrm{P}_{\mathrm{Emax} 1}=$ maximum expiratory pressure measured with plethysmograph } \\
\hline $\mathrm{P}_{\mathrm{Emax} 2}=$ maximum expiratory pressure measured with MicroRPM & \\
\hline SNIP $=$ sniff nasal inspiratory pressure & \\
\hline
\end{tabular}

Table 2. Subjects' Diagnoses

\begin{tabular}{lc}
\hline \hline \multicolumn{1}{c}{ Diagnosis } & $n(\%)$ \\
\hline Amyotrophic lateral sclerosis & $17(30.9)$ \\
Becker muscular dystrophy & $2(3.6)$ \\
Congenital myasthenic syndrome & $3(5.5)$ \\
Dejerine-Sottas disease & $1(1.8)$ \\
Duchenne muscular dystrophy & $3(5.5)$ \\
Facioscapulohumeral muscular dystrophy & $2(3.6)$ \\
Inclusion body myopathy & $1(1.8)$ \\
Limb-girdle muscular dystrophy & $6(10.9)$ \\
Mitochondrial myopathy & $1(1.8)$ \\
Myasthenia gravis & $4(7.3)$ \\
Myotonic dystrophy type 1 & $1(1.8)$ \\
Myotonic dystrophy type 2 & $2(3.6)$ \\
Pompe disease & $2(3.6)$ \\
Steinert disease & $10(18.2)$ \\
\hline
\end{tabular}

The correlations of the respiratory variables sniff nasal inspiratory pressure, $\mathrm{FVC}, \mathrm{FEV}_{1}, \mathrm{TLC}, \mathrm{P}_{\mathrm{aO}}, \mathrm{P}_{\mathrm{aCO}_{2}}$, and $\mathrm{P}_{\text {Imax }}$, and $\mathrm{P}_{\text {Emax }}$ measured with the plethysmograph and the portable device are shown in Table 3. All correlations were significant, except for the correlations of $\mathrm{P}_{\text {Imax }}$ and $\mathrm{P}_{\text {Emax }}$ with $\mathrm{P}_{\mathrm{aCO}_{2}}, \mathrm{P}_{\mathrm{aO}}$, and TLC (expressed as a percent-

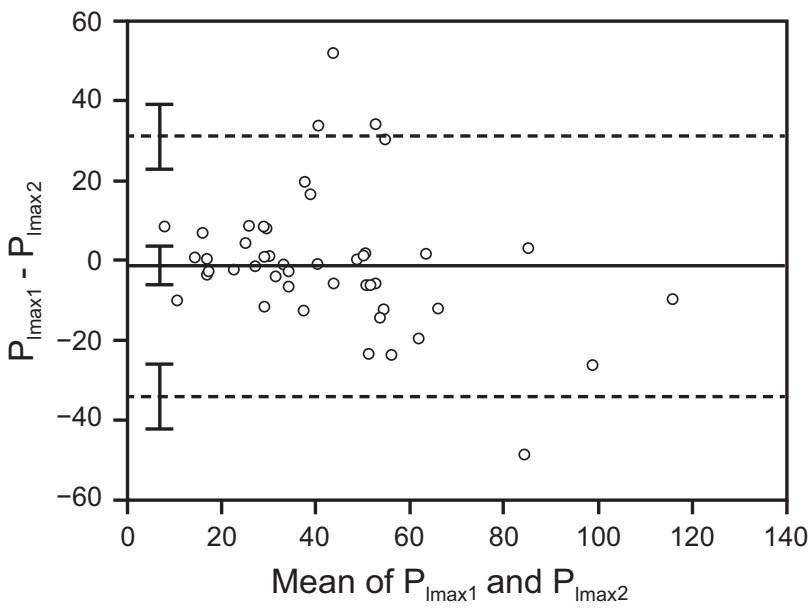

Fig. 1. Bland-Altman plot, representing the agreement between the portable equipment and plethysmograph for $\mathrm{P}_{\text {Imax }}$. The mean difference between the equipment for $\mathrm{P}_{\operatorname{Imax}}$ was not significantly different from zero (the value is included in the mean difference $\mathrm{Cl}$ ), which shows a good agreement. $\mathrm{P}_{\mathrm{Imax}}=$ maximum inspiratory pressure. Solid line shows mean; dotted lines denote \pm 1.96 SD.

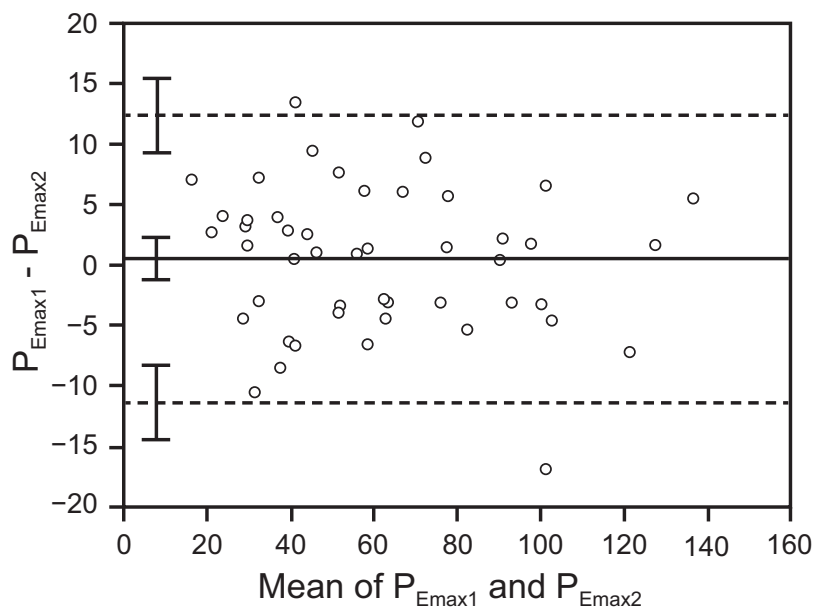

Fig. 2. Bland-Altman plot, representing the agreement between the portable equipment and plethysmograph for $\mathrm{P}_{\text {Emax }}$. The mean difference between the equipment for $P_{E \max }$ was not significantly different from zero (the value is included in the mean difference $\mathrm{Cl})$, which shows a good agreement. $\mathrm{P}_{\text {Emax }}=$ maximum expiratory pressure. Solid line shows mean; dotted lines denote \pm 1.96 SD.

age of predicted). Sniff nasal inspiratory pressure showed a strong correlation with both measurements of $\mathrm{P}_{\text {Imax }}$ $(P<.001$ each $)$. Moreover, moderate correlations were observed between FVC (measured in $\mathrm{L}$ ) and measurements of $\mathrm{P}_{\text {Imax }}$ and $\mathrm{P}_{\mathrm{Emax}}$ on both types of equipment $(P<.001$ each).

\section{Discussion}

Assessment of respiratory muscle weakness in patients with NMD is difficult because lung volumes near normal 
Table 3. Heat Map of Correlations Between $\mathrm{P}_{\operatorname{Imax} 1}, \mathrm{P}_{\operatorname{Imax} 2}, \mathrm{P}_{\mathrm{Emax} 1}, \mathrm{P}_{\mathrm{Emax} 2}$ and All the Other Variables

\begin{tabular}{|c|c|c|c|c|c|c|c|c|c|c|c|c|c|}
\hline & $\mathrm{P}_{\text {Imax } 1}$ & $\mathrm{P}_{\operatorname{Imax} 2}$ & $\mathrm{P}_{\text {Emax } 1}$ & $\mathrm{P}_{\text {Emax } 2}$ & SNIP Test & FVC (\%) & FVC (L) & $\operatorname{FEV}_{1}(\%)$ & $\mathrm{FEV}_{1}(\mathrm{~L})$ & TLC (\%) & TLC (L) & $\mathrm{P}_{\mathrm{aCO}_{2}}$ & $\mathrm{P}_{\mathrm{aO}_{2}}$ \\
\hline $\mathrm{P}_{\text {Imax } 1}$ & 1.00 & 0.79 & 0.61 & 0.60 & 0.78 & 0.38 & 0.54 & 0.31 & 0.48 & 0.25 & 0.38 & -0.32 & 0.29 \\
\hline $\mathrm{P}_{\operatorname{Imax} 2}$ & 0.79 & 1.00 & 0.72 & 0.73 & 0.76 & 0.34 & 0.59 & 0.30 & 0.53 & 0.26 & 0.48 & -0.09 & -0.04 \\
\hline $\mathrm{P}_{\text {Emax } 1}$ & 0.61 & 0.72 & 1.00 & 0.98 & 0.62 & 0.31 & 0.58 & 0.28 & 0.53 & 0.12 & 0.51 & -0.12 & 0.10 \\
\hline $\mathrm{P}_{\text {Emax2 }}$ & 0.60 & 0.73 & 0.98 & 1.00 & 0.60 & 0.34 & 0.57 & 0.32 & 0.51 & 0.18 & 0.52 & -0.01 & -0.01 \\
\hline SNIP test & 0.78 & 0.76 & 0.62 & 0.60 & 1.00 & 0.35 & 0.49 & 0.31 & 0.46 & 0.22 & 0.31 & -0.22 & 0.16 \\
\hline $\mathrm{FVC}, \%$ & 0.38 & 0.34 & 0.31 & 0.34 & 0.35 & 1.00 & 0.76 & 0.96 & 0.70 & 0.82 & 0.66 & -0.50 & 0.22 \\
\hline FVC, L & 0.54 & 0.59 & 0.58 & 0.57 & 0.49 & 0.76 & 1.00 & 0.75 & 0.96 & 0.50 & 0.83 & -0.55 & 0.39 \\
\hline $\mathrm{FEV}_{1}, \%$ & 0.31 & 0.30 & 0.28 & 0.32 & 0.31 & 0.96 & 0.75 & 1.00 & 0.76 & 0.74 & 0.61 & -0.58 & 0.26 \\
\hline FEV, L & 0.48 & 0.53 & 0.53 & 0.51 & 0.46 & 0.70 & 0.96 & 0.76 & 1.00 & 0.39 & 0.72 & -0.62 & 0.43 \\
\hline TLC, $\%$ & 0.25 & 0.26 & 0.12 & 0.18 & 0.22 & 0.82 & 0.50 & 0.74 & 0.39 & 1.00 & 0.66 & -0.23 & -0.07 \\
\hline TLC, L & 0.38 & 0.48 & 0.51 & 0.52 & 0.31 & 0.66 & 0.83 & 0.61 & 0.72 & 0.66 & 1.00 & -0.20 & 0.17 \\
\hline $\mathrm{P}_{\mathrm{aCO}_{2}}$ & -0.32 & -0.09 & -0.12 & -0.01 & -0.22 & -0.50 & -0.55 & -0.58 & -0.62 & -0.23 & -0.20 & 1.00 & -0.54 \\
\hline $\mathrm{P}_{\mathrm{aO}_{2}}$ & 0.29 & -0.04 & 0.10 & -0.01 & 0.16 & 0.22 & 0.39 & 0.26 & 0.43 & -0.07 & 0.17 & -0.54 & 1.00 \\
\hline \multicolumn{14}{|c|}{$\begin{array}{l}\mathrm{P}_{\text {Imax1 }}=\text { maximum inspiratory pressure measured with plethysmograph } \\
\mathrm{P}_{\text {Imax } 2}=\text { maximum inspiratory pressure measured with MicroRPM } \\
\mathrm{P}_{\text {Emax } 1}=\text { maximum expiratory pressure measured with plethysmograph } \\
\mathrm{P}_{\text {Emax2 }}=\text { maximum expiratory pressure measured with MicroRPM } \\
\mathrm{SNIP}=\text { sniff nasal inspiratory pressure } \\
\text { TLC }=\text { total lung capacity }\end{array}$} \\
\hline
\end{tabular}

may accompany significant muscle weakness. ${ }^{28}$ Similarly, we found that the mean TLC was normal $(86 \%$ of predicted), and that $\mathrm{FVC}$ and $\mathrm{FEV}_{1}$ were decreased $\mathrm{FVC}$ was $69 \%$ and $\mathrm{FEV}^{1}$ was $72 \%$ of predicted, respectively, whereas the mean values of all maximum respiratory pressures, including $\mathrm{P}_{\text {Imax }}, \mathrm{P}_{\text {Emax }}$, and sniff nasal inspiratory pressure, were decreased. $\mathrm{P}_{\text {Imax }}$ is the test most used in standard clinical practice test to evaluate respiratory muscle weakness, ${ }^{11}$ although its sole use may tend to overdiagnose weakness. ${ }^{11,29}$

Dimitriadis et al $^{22}$ showed that the evaluation of the reproducibility of $\mathrm{P}_{\text {Imax }}$ and $\mathrm{P}_{\text {Emax }}$ measured with the portable device had a high intraclass correlation coefficient for both. Our study also found that $\mathrm{P}_{\text {Imax }}$ and $\mathrm{P}_{\text {Emax }}$ were similar with the portable device and the plethysmograph, with bias close to zero, which indicated good agreement between the 2 methodologies and proper calibration of the equipment. Thus, similar to findings in healthy individuals, ${ }^{22}$ our results confirmed that the difference between the methods was not clinically relevant in patients with NMD and that assessing $\mathrm{P}_{\text {Imax }}$ and $\mathrm{P}_{\text {Emax }}$ by using the portable equipment was reliable.

The characteristics of these methodologies, however, differed substantially. Evaluation of maximum respiratory pressures with the portable equipment is inexpensive, can be performed in any place (not necessarily in a laboratory), and by several types of health professionals (not necessarily a cardiopneumology technician). In contrast, the plethysmograph is approximately 40 times more expensive, with evaluation of maximum respiratory pressures performed only in a hospital and by a trained technician.

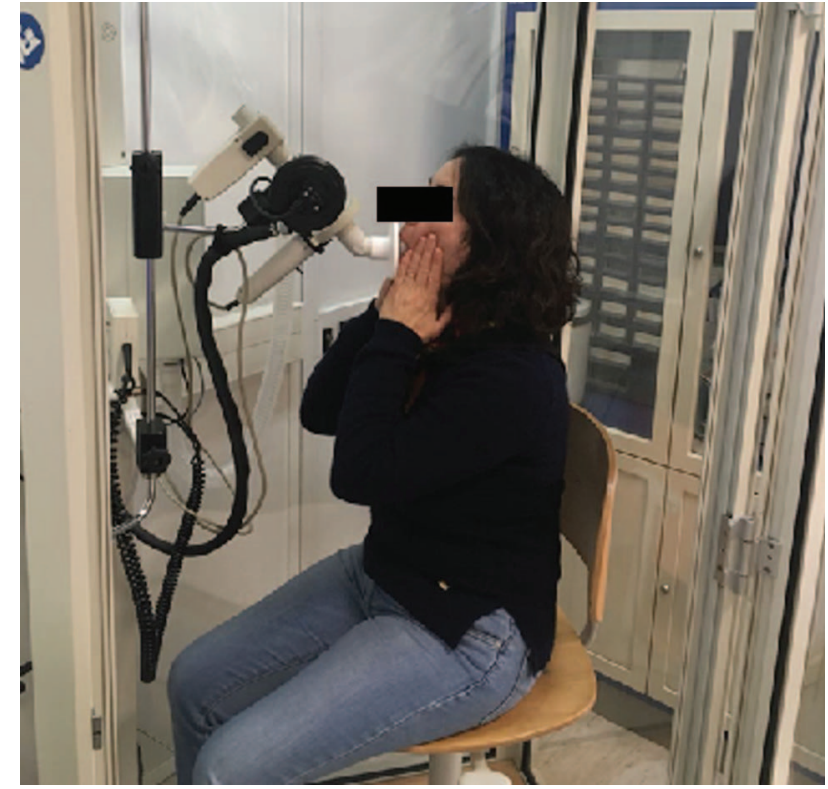

Fig. 3. Evaluation of maximum respiratory pressures in the plethysmograph.

An example of both evaluations can be found in (Figs. 3 and 4). Our results indicated that the portable equipment and our accepted standard assessment of $\mathrm{P}_{\text {Imax }}$ and $\mathrm{P}_{\text {Emax }}$ were equivalent, with the lack of differences in the results obtained when using the 2 methodologies, which indicated that the portable device was reliable and may be used at the bedside.

The development of respiratory failure is a significant predictor of early death, ${ }^{30}$ which indicates that the assess- 


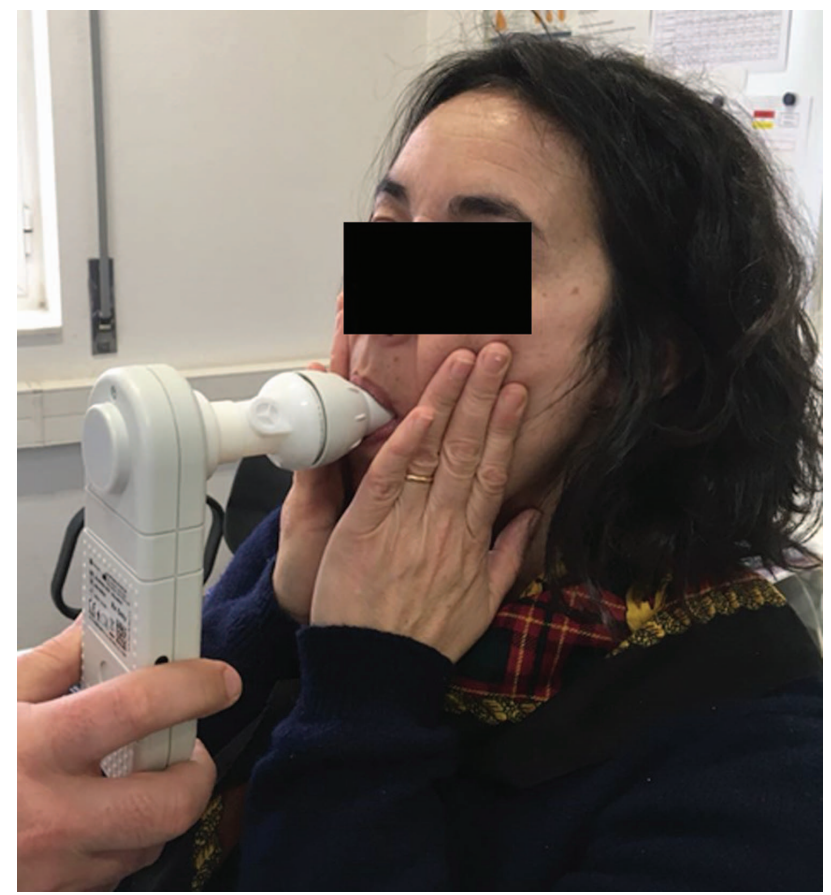

Fig. 4. Evaluation of maximum respiratory pressures with the portable equipment.

ment of maximum respiratory pressures should be complementary to the assessment of lung function and arterial blood gas. Patients who no longer have the ability to undergo plethysmography or spirometry, or to even be moved to a lung function testing laboratory, especially those with bulbar dysfunction, including some excluded from this study, may, therefore, be evaluated at the bedside with a simple and portable device.

$\mathrm{P}_{\text {Imax }}$ and the sniff nasal inspiratory pressure have been found to be correlated in healthy individuals ${ }^{12,18}$ and in patients with COPD. ${ }^{31}$ Similarly, our study confirmed previous findings ${ }^{32}$ that indicated a good correlation between sniff nasal inspiratory pressure and $\mathrm{P}_{\mathrm{Imax}}$ in subjects with NMD. This correlation indicated that $\mathrm{P}_{\text {Imax }}$ and sniff nasal inspiratory pressure are not interchangeable. Rather, they are complementary and, whenever possible, should be measured at the same time. Routine evaluation of both may enable sniff nasal inspiratory pressure to be extremely useful from the time a patient deteriorates and cannot, for example, perform the $\mathrm{P}_{\text {Imax }}$ maneuver.

Spirometry in patients with NMD is widely used to assess respiratory muscle function. A $>20 \%$ reduction in difference of FVC measured in the upright and supine positions is diagnostic of diaphragmatic weakness. ${ }^{30,33}$ $\mathrm{P}_{\text {Imax }}$ and FVC have been found to be correlated in patients with NMD. ${ }^{34}$ Similarly, we found that FVC, measured inliters, correlated significantly with $\mathrm{P}_{\mathrm{Imax}}$ and $\mathrm{P}_{\mathrm{Emax}}$ measured by both plethysmography and the portable device. Although these correlations were moderate, they reinforced the importance of assessing muscle pressures in patients with NMD, not only as a complement of lung function testing but also in those unable to undergo spirometry.

Of the 17 subjects in our study with FVC $>80 \%$ of predicted, only 2 patients had normal $\mathrm{P}_{\text {Imax }}$ and $\mathrm{P}_{\text {Emax }}$ measured with the plethysmograph and 4 patients had normal $\mathrm{P}_{\text {Imax }}$ and $\mathrm{P}_{\text {Emax }}$ measured with the MicroRPM method, and only 3 ( 2 with normal $P_{\text {Imax }}$ ) had normal sniff nasal inspiratory pressure. These findings may be due to the curvilinear relationship between FVC and respiratory muscle strength, which results in substantial weakness while $\mathrm{FVC}$ is within its normal range. ${ }^{30,35} \mathrm{We}$ also observed significant moderate correlations between $\mathrm{FEV}_{1}$ and TLC (measured in liters) and some maximum respiratory pressures, in agreement with results that show statistically significant correlations between maximum respiratory pressures and $\mathrm{FEV}_{1}(\%)$ and $\mathrm{FVC}(\%)$ in patients with amyotrophic lateral sclerosis, ${ }^{36}$ and between $\mathrm{P}_{\mathrm{Imax}}$ and $\mathrm{P}_{\mathrm{Emax}}$, and $\mathrm{FEV}_{1}(\mathrm{~L}), \mathrm{FVC}(\mathrm{L})$, and TLC (L) in patients with COPD. ${ }^{37}$ In contrast, a study of subjects with motor neuron disease found no correlations of $\mathrm{P}_{\text {Imax }}$ and $\mathrm{P}_{\mathrm{Emax}}$ with $\mathrm{P}_{\mathrm{aCO}}$, although the sniff nasal inspiratory pressure was negatively correlated with $\mathrm{P}_{\mathrm{aCO}_{2}}$ in subjects without bulbar dysfunction only. ${ }^{38}$

This prospective study demonstrated the reliability of measuring $\mathrm{P}_{\text {Imax }}$ and $\mathrm{P}_{\text {Emax }}$ with portable equipment and $\mathrm{P}_{\text {Imax }}$ and $\mathrm{P}_{\text {Emax }}$ correlation with the sniff nasal inspiratory pressure in subjects with NMD. However, this study was limited by the possible presence of nasal obstruction without clinical repercussions in assessing sniff nasal inspiratory pressure, despite our exclusion of subjects with nasal anatomic abnormalities because the latter was not evaluated by rhinoscopy; the absence of leak in our equipment, which could interfere with the recorded pressures and mistakenly reflected the pressure generated by the cheeks and the muscles of the mouth, which is not avoided with the support of the cheeks; and the lack of performance of a test and re-test, although this limitation was minimized by the number of maneuvers performed. In addition, sniff nasal inspiratory pressure assessment was performed with the contralateral nostril open, although sniff nasal inspiratory pressure values measured with the contralateral nostril occluded are systematically greater ${ }^{9}$; and sleep studies were not performed in all the subjects to exclude obstructive sleep apnea as a cause of daytime hypercapnia, despite the frequency of apneas and hypopneas during sleep in patients with NMD due to the combination of respiratory muscle weakness and upper airway obstruction. ${ }^{5}$ 


\section{Conclusions}

This study found that measuring $\mathrm{P}_{\operatorname{Imax}}$ and $\mathrm{P}_{\mathrm{Emax}}$ with a portable device was equivalent to our accepted standard method (a plethysmograph) in subjects with NMD. In addition, the noninvasive evaluation of the sniff nasal inspiratory pressure with the portable equipment provided a very good measurement of the maximum strength of the inspiratory muscles, with the sniff nasal inspiratory pressure showing good correlation with $\mathrm{P}_{\text {Imax }}$. The evaluation of maximum respiratory pressures with portable equipment can be useful in the evaluation of patients with NMD whose condition deteriorates and they lose the ability to undergo plethysmography or spirometry, or to even go to a laboratory. Routine assessment of sniff nasal inspiratory pressure in patients with NMD may allow the noninvasive monitoring of these patients who can no longer be evaluated by other methods.

\section{REFERENCES}

1. Bhatt JM. The Epidemiology of Neuromuscular Diseases. Neurol Clin 2016;34(4):999-1021.

2. Hughes PD, Polkey MI, Kyroussis D, Hamnegard CH, Moxham J, Green M. Measurement of sniff nasal and diaphragm twitch mouth pressure in patients. Thorax 1998;53(2):96-100.

3. Perrin C, Unterborn JN, Ambrosio CD, Hill NS. Pulmonary complications of chronic neuromuscular diseases and their management. Muscle Nerve 2004;29(1):5-27.

4. Sclauser Pessoa IM, Franco Parreira V, Fregonezi GA, Sheel AW, Chung F, Reid WD. Reference values for maximal inspiratory pressure: a systematic review. Can Respir J 2014;21(1):43-50.

5. Lisboa C, Díaz O, Fadic R. Noninvasive mechanical ventilation in patients with neuromuscular diseases and in patients with chest restriction. Arch Bronconeumol 2003;39(7):314-320.

6. Rocha JA, Miranda MJ. Ventilatory dysfunction in motor neuron disease: when and how to act? Acta Med Port 2007;20(2):157165.

7. Radunovic A, Annane D, Rafiq MK, Brassington R, Mustfa N. Mechanical ventilation for amyotrophic lateral sclerosis/motor neuron disease. Cochrane Database Syst Rev 2017;10:CD004427.

8. Fitting JW. Sniff nasal inspiratory pressure: simple or too simple? Eur Respir J 2006;27(5):881-883.

9. Martínez-Llorens J, Ausín P, Roig A, Balañá A, Admetlló M, Muñoz L, Gea J. Nasal inspiratory pressure: an alternative for the assessment of inspiratory muscle strength? Arch Bronconeumol 2011;47(4):169-175.

10. Hamnegård $\mathrm{CH}$, Wragg S, Kyroussis D, Aquilina R, Moxham J, Green M. Portable measurement of maximum mouth pressures. Eur Respir J 1994;7(2):398-401.

11. Severino FG, Resqueti VR, Bruno SS, Azevedo IG, Vieira RH, Fregonezi GA. Comparison between a national and a foreign manovacuometer for nasal inspiratory pressure measurement. Rev Bras Fisioter 2010;14(5):426-431.

12. Maillard JO, Burdet L, van Melle G, Fitting JW. Reproducibility of twitch mouth pressure, sniff nasal inspiratory pressure, and maximal inspiratory pressure. Eur Respir J 1998;11(4):901-905.

13. Kaminska M, Noel F, Petrof BJ. Optimal method for assessment of respiratory muscle strength in neuromuscular disorders using sniff nasal inspiratory pressure (SNIP). PLoS One 2017;12(5): e0177723.
14. Black LF, Hyatt RE. Maximal respiratory pressures: normal values and relationship to age and sex. Am Rev Respir Dis 1969; 99(5):696-702.

15. Wilson SH, Cooke NT, Edwards RH, Spiro SG. Predicted normal values for maximal respiratory pressures in caucasian adults and children. Thorax 1984;39(7):535-538.

16. Morales P, Sanchis J, Cordero PJ, Díez JL. Maximum static respiratory pressures in adults. The reference values for a Mediterranean Caucasian population. Arch Bronconeumol 1997;33(5): 213-219.

17. American Thoracic Society/European Respiratory Society. ATS/ERS Statement on respiratory muscle testing. Am J Respir Crit Care Med 2002;166(4):518-624.

18. Uldry C, Fitting JW. Maximal values of sniff nasal inspiratory pressure in healthy subjects. Thorax 1995;50(4):371-375.

19. Terzi N, Orlikowski D, Fermanian C, Lejaille M, Falaize L, Louis A, et al. Measuring inspiratory muscle strength in neuromuscular disease: one test or two? Eur Respir J 2008;31(1):93-98.

20. Héritier F, Rahm F, Pasche P, Fitting JW. Sniff nasal inspiratory pressure. A noninvasive assessment of inspiratory muscle strength. Am J Respir Crit Care Med 1994;150(6 Part 1):1678-1683.

21. Steier J, Kaul S, Seymour J, Jolley C, Rafferty G, Man W, et al. The value of multiple tests of respiratory muscle strength. Thorax 2007; 62(11):975-980.

22. Dimitriadis Z, Kapreli E, Konstantinidou I, Oldham J, Strimpakos $\mathrm{N}$. Test/ retest reliability of maximum mouth pressure measurements with the MicroRPM in healthy volunteers. Respir Care 2011;56(6):776-782.

23. Johns MW. A new method for measuring daytime sleepiness: the Epworth sleepiness scale. Sleep 1991;14(6):540-545.

24. Miller MR, Hankinson J, Brusasco V, Burgos F, Casaburi R, Coates A, et al; ATS/ERS Task Force. Standardisation of spirometry. Eur Respir J 2005;26(2):319-338.

25. Quanjer PH, Stanojevic S, Cole TJ, Baur X, Hall GL, Culver BH, et al; ERS Global Lung Function Initiative. Multi-ethnic reference values for spirometry for the 3-95 year age range: the global lung function 2012 equations. Report of the Global Lung Function Initiative (GLI), ERS Task Force to establish improved Lung Function Reference Values. Eur Respir J 2012;40(6):1324-1343.

26. Altman DG, Bland JM. Measurement in medicine: the analysis of method comparison studies. Statistician 1983;32(3):307-317.

27. Walker HM. The contributions of Karl Pearson. J Am Stat Assoc 1958;53(281):11-22.

28. Soliman MG, Higgins SE, El-Kabir DR, Davidson AC, Williams AJ, Howard RS. Non-invasive assessment of respiratory muscle strength in patients with previous poliomyelitis. Respir Med 2005;99(10): 1217-1222.

29. Steier J, Kaul S, Seymour J, Jolley C, Rafferty G, Man W, et al. The value of multiple tests of respiratory muscle strength. Thorax 2007; 62(11):975-980.

30. Schoser B, Fong E, Geberhiwot T, Hughes D, Kissel JT, Madathil $\mathrm{SC}$, at al. Maximum inspiratory pressure as a clinically meaningful trial endpoint for neuromuscular diseases: a comprehensive review of the literature. Orphanet J Rare Dis 2017;12(1):52.

31. Uldry C, Janssens JP, de Muralt B, Fitting JW. Sniff nasal inspiratory pressure in patients with chronic obstructive pulmonary disease. Eur Respir J 1997;10(6):1292-1296.

32. Stefanutti D, Benoist MR, Scheinmann P, Chaussain M, Fitting JW. Usefulness of sniff nasal pressure in patients with neuromuscular or skeletal disorders. Am J Respir Crit Care Med 2000;162(4 part 1): 1507-1511.

33. Allen SM, Hunt B, Green M. Fall in vital capacity with posture. Br J Dis Chest 1985;79(3):267-271. 
34. Schmidt EP, Drachman DB, Wiener CM, Clawson L, Kimball R, Lechtzin N. Pulmonary predictors of survival in amyotrophic lateral sclerosis: use in clinical trial design. Muscle Nerve 2006;33(1):127-132.

35. Braun NM, Arora NS, Rochester DF. Respiratory muscle and pulmonary function in polymyositis and other proximal myopathies. Thorax 1983;38(8):616-623.

36. Park KH, Kim RB, Yang J, Oh JH, Park SY, Kim DG, et al. Reference Range of Respiratory Muscle Strength and Its Clinical Ap- plication in Amyotrophic Lateral Sclerosis: A Single-Center Study. J Clin Neurol 2016;12(3):361-367.

37. Terzano C, Ceccarelli D, Conti V, Graziani E, Ricci A, Petroianni A. Maximal respiratory static pressures in patients with different stages of COPD severity. Respir Res 2008;9(1):8.

38. Chaudri MB, Liu C, Watson L, Jefferson D, Kinnear WJ. Sniff nasal inspiratory pressure as a marker of respiratory function in motor neuron disease. Eur Respir J 2000;15(3):539-542.

This article is approved for Continuing Respiratory Care Education credit. For information and to obtain your CRCE

(free to AARC members) visit 